\title{
SISTEMAS DETERMINADORES DA NACIONALIDADE DA PESSOA JURÍDICA E O DIREITO INTERNACIONAL PRIVADO BRASILEIRO
}

\author{
CÉLIO DE JESUS LOBÃO FERREIRA \\ (Auxiliar de Ensino de Direito Internacional Privado.)
}

A nacionalidade das pessoas jurídicas não é assunto pacífico, na doutrina e na legislação. Alguns autores aceitam que a lei pode conceder nacionalidade à pessoa jurídica, enquanto outros, principalmente os seguidores da teoria da ficção, sustentam ponto de vista contrário.

NIBOYET chega mesmo a utilizar argumento nada jurídico para negar a nacionalidade. Sustenta que um país de 40 milhões de habitantes e 500 mil sociedades, teria uma população de 40 milhões e 500 mil nacionais. (') Argumento, sem dúvida alguma, insustentável. A concessão de nacionalidade à pessoa jurídica não tem como conseqüência impor à estatística que a inclua como integrante da população. Além do mais, há confusão entre o conceito de habitantes, nacionais e população.

MARTIN WOLFF fundamenta sua negativa no fato de que a pessoa jurídica não presta serviço militar nem tem direitos políticos. Ora, há indivíduos que jamais prestarão serviço militar ou terão direitos políticos e nem por isso deixarão de ter nacionalidade. Por outro lado, há países que admitem a prestação do serviço militar por parte de estrangeiros. É oportuno lembrar que, no Direito Brasileiro, pessoas jurídicas podem votar em eleições classistas.

Legislações de alguns países silenciam sôbre a nacionalidade das pessoas jurídicas, o que não impede de os tribunais decidirem sôbre - assunto. A Argentina não concede nacionalidade à pessoa jurídica, em decorrência de experiência colhida no conflito entre a Província de Santa Fé e o Banco de Londres y Rio del Plata, em 1876. Como o estabelecimento de crédito não obedecesse determinação legal, foram

1. NIBOYET, $1 / 87$, nota 1 . 
retirados trinta mil pesos de seus cofres e promovida a liqüidação da sucursal. O gerente solicitou proteção diplomática ao ministro inglês que qualificou essa medida como grande ofensa que jamais havia sido feita contra súdito de outro país. $\left({ }^{2}\right)$

Dêsse conflito surgiu a doutrina IRIGOYEN: "Las personas jurídicas deben exclusivamente su existencia a la ley del país que las autoriza y por consiguiente, ellas no son, ni nacionales, ni extranjeras. La sociedad anónima es una persona jurídica distinta de los individuos que la forman, y aunque ella sea exclusivamente formada por ciudadanos extranjeros, no tiene derecho a la protección diplomática". ( $\left.{ }^{3}\right)$

Dentro dêsse ponto de vista, ROMERO DEL PRADO sustenta que a concessão de nacionalidade tem como conseqüência que a pessoa jurídica possa ser objeto de proteção diplomática. Ora, a proteção diplomática absurda decorre da prepotência de país mais forte contra outro mais fraco e nunca do instituto jurídico. Com ou sem nacionalidade existirá sempre essa proteção que tanto pode revestirse de medidas belicosas quanto de caráter econômico.

Apesar de opiniões contrárias, a realidade é a de que a nacionalidade da pessoa jurídica é aceita em conclaves internacionais, pela legislação e jurisprudência de vários países, por juristas de renome e até mesmo por aquêles que a negam, quando se referem a pessoas jurídicas estrangeiras, em oposição às nacionais. Outros disfarçam essa aceitação com outros nomes, como "allégeance", "appartenance". Dentre os conclaves onde ocorreu essa aceitação, mencionaremos a Conferência Pan-Americana de Havana; Instituto de Direito Internacional, sessões de 1891 em Hamburgo e de 1897 em Copenhague; Congresso Internacional de Sociedades por Ações; Côrte Permanente de Haia.

Jurìdicamente, não se justifica a obstinação nessa recusa. O conceito é jurídico, como é jurídico o conceito de pessoa e a lei é que estabelece se a pessoa jurídica tem ou não nacionalidade. Deve-se raciocinar em têrmos de Ciência do Direito e não de Estatística. Pode acontecer que a lei de determinado país deixe de atribuir nacionalidade à pessoa jurídica, porém essa circunstância não serve para invalidar o instituto. Há países da África onde não se pode dizer que indivíduos de determinada raça sejam pessoas, tantas são as restrições que lhe são impostas e, dessas, a menor é a de votar e ser votado.

2. ROMERO DEL PRADO, $1 / 924$.

3. ROMERO DEL PRADO, 1/925 e W. GOLDSCHMIDT, $11 / 70$. 
Vários sistemas têm sido propostos para determinar a nacionalidade da pessoa jurídica. Dentre êsses, consideramos mais importantes: o do centro de exploração; o do lugar da constituição; sede social; nacionalidade dos sócios; sistema do contrôle.

O primeiro, consiste em conceder, à pessoa jurídica, a nacionalidade do país onde tem o centro de exploração, onde exerce suas "labores fisícas principales". $\left({ }^{4}\right) \mathrm{Nada}$ mais interessa na determinação da nacionalidade, senão o lugar onde a pessoa jurídica desenvolve suas atividades.

Critica-se o sistema porque pode haver mais de um centro de exploração, como no caso da Companhia do Leste da India, criada na Inglaterra a fim de exercer suas atividades em vários países. Outras vêzes, o centro de exploração é indeterminado, como a companhia cujos carros-leito correm através de países europeus.

Os defensores do sistema apresentam como vantagem a de não favorecer a fraude e também por ser o país de exploração mais diretamente interessado. Na hipótese de existir mais de um centro de exploração estabelecem, como determinador da nacionalidade, o local onde se concentra maior atividade da pessoa jurídica, denominado, pelos partidários do sistema, de principal estabelecimento.

Tem a preferência de PILLET, ASSER, LYON CAHEN e outros. Encontramos em alguns acórdãos de tribunais franceses, como a decisão datada de 15 de maio de 1931, negando nacionalidade francesa à Société Remington, sob o fundamento de não se encontrar na França "son centre principal d'établissement", localizado nos Estados Unidos, onde eram fabricadas as máquinas que a filial francesa limitava-se a vender.

Somos contrários ao sistema. Favorece a fraude, porquanto a nacionalidade efetiva é a do país onde estão os órgãos de direção, de onde a emprêsa é dirigida, em função de interêsses que, na maioria das vêzes, não coincidem com os do país onde se localiza o centro de exploração.

Como segundo sistema, temos o do lugar da constituição. A nacionalidade da pessoa jurídica será a do país sob cuja lei foi criada, lei essa a que obedeceu para ter existência jurídica. Não interessa saber onde foi subscrito o capital social, onde pretende exercer suas atividades ou a localização da sede social. A nacionalidade será a do país cuja lei foi observada no momento da criação da pessoa jurídica. 
WOLFF lembra que êsse sistema originou-se na concepção arcaica de que a concessão de personalidade legal a um ser inanimado é um ato excepcional de graça e o estado que a concede impõe o direito segundo o qual a pessoa artificial viverá $\left({ }^{5}\right)$, enquanto SAVATIER entende haver aplicação da autonomia da vontade, com a escolha da lei aplicável à pessoa jurídica.

Nenhum outro sistema presta-se melhor à fraude, tanto assim que foi rejeitado pelo Congresso de Sociedades por Ações, de 1889, realizado em Paris, por considerá-lo favorável à fraude e à constituição de sociedades no estrangeiro, com $\circ$ fim exclusivo de iludir disposições de leis nacionais. $\left.{ }^{(}\right)$Nesse mesmo sentido, MARTIN WOLFF ao observar que as razões da escolha de um país, para constituir-se a pessoa jurídica, nem sempre são muito honradas. $\left({ }^{7}\right)$

Financistas franceses vão de trem a Bruxelas, pela manhã, a fim de formarem uma sociedade, perante o notário belga, regressando à tarde. Segundo THALLER, tal sociedade não será belga. $\left({ }^{8}\right)$ Que não diria o tratadista a respeito de pessoas jurídicas constituídas por meio de procuradores, porque os financistas não querem perder tempo, comparecendo ao país da constituição?

Tribunal francês negou validade ao lugar da constituição considerando francesa a sociedade The Moulin Rouge Attractions Limited constituída em Londres para exploração do estabelecimento parisiense "Moulin Rouge", inteiramente composta por franceses, residentes em Paris, onde se encontrava a sede social e o centro de exploração. Os fundadores recorreram à lei inglêsa a fim de apresentá-la como nacional daquele país. $\left({ }^{9}\right)$

Êsse sistema goza da preferência das legislações anglo-americana e soviética. Parece merecer também a simpatia de ANDRE WEISS ao considerar francesas "ies personnes morales créées par la loi française" e estrangeiras "les personnes morales à la naissance desquelles est intervenu un souverain ou un législateur étranger." $\left({ }^{10}\right)$

Não é aconselhável a adoção dêsse sistema, porquanto fica ao inteiro arbítrio dos fundadores da pessoa jurídica a fixação da nacionalidade, sem outro critério senão o de satisfazer seus interêsses. Os países econômicamente mais fracos adotam-no juntamente com

\footnotetext{
5. ROMERO DEL PRADO, $1 / 914$.

6. WOLFF, 286.

7. WOLFF, 287.

8. ROMERO DEL PRADO, $1 / 915$.

9. ROMERO DEL PRADO, 1/919.

10. WEISS, 312.
} 
o da sede social. Não é a solução, mas evita mal maior que seria a aceitação do critério do lugar da constituição com exclusividade.

Como terceiro sistema, indicamos o da sede social, segundo o qual a nacionalidade será a do país onde se encontra a sede administrativa, onde se reúnem as assembléias, a diretoria, enfim, onde estão localizados os órgãos que efetivamente dirigem a pessoa jurídica.

A Côrte de Apelação de Paris, em acórdão datado de 21 de maio de 1957, definiu sede social como o lugar no qual se reúnem as assembléias gerais, em que se encontram os órgãos de direção superior e de contrôle e onde está sediado seu conselho de administração. ('1) A decisão tem amplitude capaz de alcançar fraudes usadas e, muitas vêzes, pacificamente aceitas. Realmente, da enumeração constam organes de direction supérieure et de contrôle. Tratando-se de diretoria, com poder de mando restrito e obedecendo a diretrizes traçadas por órgãos superiores, órgãos êsses que exercem completo contrôle sôbre a pessoa jurídica, não há como falar-se em sede social, no país em que funciona essa diretoria.

A doutrina estabelece distinção entre a sede social efetiva e a sede social fictícia. A primeira será onde se situam os órgãos que realmente dirigem a pessoa jurídica e a sede social fictícia, o local que os dirigentes apresentam como certro de administração da pessoa jurídica. Conforme acentua NIBOYET, essa sede social fictícia consiste, algumas vêzes, em simples enderêço no qual funciona uma administração esquelética ou mesmo administração alguma. (12)

A fim de evitar tais expedientes, o Instituto de Direito Internacional, em 1891, votou resolução, segundo a qual deve-se considerar como país de origem de uma sociedade por ações, aquêle onde haja estabelecido, sem fraude, sua sede social legal. Essa disposição foi transcrita no art. $70^{\circ}$ do Dahir marroquino, de 12 de agôsto de 1913: "La nationalité d'une société est déterminée par la loi du pays dans lequel a été établi sans fraude son siège social légal". $\left({ }^{13}\right)$

Pode ocorrer que a expansão da pessoa jurídica imponha a necessidade de descentralizar a administração a fim de dinamizar as atividades de filiais, deslocando setôres dessa administração, que passam a gozar de autonomia em assuntos específicos. Nesse caso, não há sede fictícia e sim filiais, que obedecem a normas ditadas pela matriz, isto é, pela sede social onde continua o centro decisório da emprêsa.

11. FRANCESCAKIS, 308 .

12. NIBOYET, $11 / 362$.

13. NIBOYET, $11 / 356$, nota 1. 
Preferido por PILLET, é o sistema tradicionalmente aceito pelos tribunais franceses, embora seu prestígio houvesse declinado durante as duas grandes guerras, voltando a ocupar lugar de destaque, não obstante a aplicação do contrôle, em casos isolados. $\left({ }^{14}\right)$

MARTIN WOLFF considera a doutrina oportuna e satisfatória porque o centro de administração dificilmente pode ser mantido em segrêdo. $\left({ }^{15}\right)$

Com a ressalva de que não nos filiamos a êsse critério, desejamos assinalar que é o melhor dentre os já mencionados. Com efeito, sua aplicação dentro do conceito rigoroso de sede social deixará pouca margem à fraude, principalmente se procurarmos saber ond? funciona a sede social, nos casos em que os dirigentes procuram mantê-la oculta.

PONTES DE MIRANDA observa: "aquêles que seguiram cegamente o sistema da sede social, com o critério da lex fori inflexível, viram, ao contato dos fatos, os perigos de tal sistema. Estrangeiros associaram-se, fixaram a sede no país e gozaram de todos os direi tos das sociedades nacionais". (16) Mais recentemente BATIFFOL esclarece que "le système du siège social a paru aussi à l'époque du liberalisme économique s'accommoder avec plus de souplesse des besoins de la société qui peut plus facilement le placer "selon ses convenances". $\left({ }^{17}\right)$ (O grifo é nosso.) Vamos mais além, tal situação, posta em evidência pelas duas conflagrações mundiais, continua imutável, com pessoas jurídicas adquirindo nacionalidade aparente a fim de usufruírem de privilégios que deveriam ficar restritos às pessoas jurídicas genuìnamente nacionais.

No critério da nacionalidade dos sócios, a pessoa jurídica terá a mesma nacionalidade da maioria dos sócios. Alguns autores registram a dificuldade em estabelecer a nacionalidade nos casos de ações ao portador ou quando não há maioria de sócios de determinada nacionalidade. Procedem essas restrições e com o surgimento do sistema do contrôle, no qual existe maior segurança na determinação da nacionalidade efetiva, o critério da nacionalidade dos sócios passou para segundo plano, na doutrina.

$\mathrm{Na}$ legislação outros horizontes surgiram, com o movimento de nacionalização de pessoas jurídicas, ocorrido em vários países do mundo, após o confisco de bens realizado pelo govêrno soviético, a partir do decreto de 17 de dezembro de 1917.

14. JEAN CHAPRAT, 32.

15. WOLFF, 284.

16. PONTES DE MIRANDA, $1 / 454$.

17. BATIFFOL, 224. 
Releva notar que o conceito de nacionalização, necessàriamente, não se encontra ligado ao programa e ideologia comunista, porquanto foi aceito no art. 103, do Código Social, que é um esquema de síntese social católica, elaborada pela União Internacional de Estudo Social de Malines, Bélgica. $\left({ }^{18}\right)$

Dentre outras nacionalizações, temos a de 17 emprêsas petrolíferas, pelo Govêrno mexicano, em 1938. A Inglaterra, em 1945 e 1946, nacionalizou o Banco da Inglaterra, indústria de ferro, de carvão, de transporte, de gás, eletricidade, telecomunicações. A França nacionalizou bancos, indústria de minérios, eletricidade, etc.

Essas emprêsas nacionalizadas, quando não passam totalmente para o patrimônio estatal, admitem, sòmente naturais do país como acionistas, numa aplicação rígida do princípio da nacionalidade dos sócios.

Finalmente, temos o sistema do contrôle, pelo qual a nacionalidade das pessoas jurídicas é a daqueles que as dirigem, direta ou indiretamente. Portanto, o elemento determinador é a nacionalidade das pessoas, físicas ou jurídicas, que exercem contrôle sôbre a pessoa jurídica.

No Brasil, segundo VALADÃO, "criou-se muito antes da 1.0 Guerra Mundial, desde o Império uma orientação caracterizada, pelo critério do "contrôle". $\left({ }^{19}\right)$ Realmente, é o que ressalta do inciso $1 .{ }^{\circ}$. do art. $3^{\circ}$, da Lei 123, de 1892: “... sociedade ou emprêsa com sede no Brasil, gerida exclusivamente por cidadãos brasileiros".

Entretanto, sòmente com a primeira grande guerra, os auiores passaram a interessar-se pelo contrôle que se consolidou na doutrina. após a Guerra de 1939, com a preocupação de saber, não a nacionalidade dos sócios e sim a daqueles que efetivamente predominam e dirigem a pessoa jurídica. NIBOYET cita o ocorrido com a sociedade Vilgrain, na qual um grupo com capital de quatro milhões dominava cento e setenta e cinco milhões, pertencentes a pequenos e médios acionistas. BARBOSA LIMA SOBRINHO refere-se a casos em que a diretoria domina a pessoa jurídica, "quando o montante das ações se acha tão distribuído que nenhum indivíduo ou grupo, que tenha mesmo grande participação na minoria, pode dominar os negócios da emprêsa". $\left({ }^{20}\right)$ Pela teoria do contrôle, a nacionalidade da pessoa jurídica será a da minoria, no primeiro exemplo e, no

\footnotetext{
18. GIUSEPPE CASSONI, 1.

19. VALADÃO, 453.

20. BARBOSA L. SOBRINHO, 118.
} 
segundo, a da diretoria ou do grupo que exercesse influência dominante sôbre essa diretoria.

A Alemanha é apontada, por ZEBALLOS, como o primeiro país a aplicar o critério do contrôle, pela lei de 4 de setembro de 1914. $\left({ }^{21}\right) \mathrm{Em}$ data posterior, vamos encontrar seus princípios na circular do Guarda de Selos, datada de 29 de fevereiro de 1916, considerando sociedade inimiga, "dès que, notoirement, sa direction ou ses capitaux sont en totalité ou en majeure partie entre les mains de sujets ennemis, car, en pareil cas, derrière la fiction du droit privé se dissimulent vivantes et agissantes des personnalités ennemies elles-mêmes". $\left({ }^{22}\right)$ Acontece que essa circular distinguia nacionalidade de direito público e nacionalidade de direito privado. Os critérios estabelecidos para a segunda não valiam para a primeira que determinariam o caráter inimigo ou não da pessoa jurídica. Não tinha consistência essa orientação, abandonada em proveito da teoria do contrôle, apesar de NIBOYET ainda insistir no estatuto jurídico e estatuto político das pessoas jurídicas, seguindo o ponto de vista da circular.

$\mathrm{Na}$ Inglaterra, os autores apresentam, como exemplo decisão da Câmara dos Lords, de 1916, modificando acórdão do Tribunal de Apelação, a fim de considerar como inimiga sociedade constituída na Inglaterra, com maioria de ações em poder de alemães. $\left({ }^{23}\right)$ Nesse mesmo sentido, o Tribunal de Milão, em 1916, atribuindo qualidade de inimiga a sociedade constituída na Itália, onde tinha a sede social, porém com predomínio de acionistas austro-húngaros. ${ }^{(24)}$ Por sua vez, o Tribunal Supremo de Nova York manteve a nacionalidade norte-americana da sociedade Fritz Schulz, apesar de 47, das 50 partes de seu capital social, pertencerem a alemães. $\left({ }^{25}\right) \mathrm{Pa}$ rece-nos que $\circ$ Direito norte-americano adotou sistema diverso, que é $\circ$ de confiscar o direito acionário em favor da Enemy Property Custodian. $\left({ }^{26}\right)$

Terminada a guerra, o contrôle foi aplicado nos tratados de Neuilly, Trianon, Saint-Germain e Versailles. $\left({ }^{27}\right)$ Nesse último, segundo GOLDSCHMIDT, em favor dos vencedores e prejuízo dos vencidos. $\left({ }^{28}\right)$ Em seguida entrou em declínio, observando BARBOSA LIMA

21. ZEBALLOS, p. 82.

22. NIBOYET, $11 / 366$.

23. WOLFF, 295.

24. ESPÍNOLA, V/497.

25. ESPÍNOLA, V/498 e WOLFF, 295, nota 54.

26. GIUSEPPE CASSONI, 86.

27. NIBOYET, $11 / 366$.

28. W. GOLDSCHMIDT, $I / / 58$. 
SOBRINHO que "subjugada a Alemanha e a Austria-Hungria aniquilada, não havia mais perigo da infiltração de capitais germânicos, em países de sólida estrutura econômica, como a Inglaterra, a França ou os Estados Unidos. Ao contrário, convinha circunscrever as medidas tomadas no calor da luta, ao próprio período da guerra, para que a Inglaterra a França, os Estados Unidos retomassem a posição anterior, como países que podiam infiltrar-se em sociedades, destinadas a viver e a atuar em território alheio". $\left({ }^{29}\right)$

No entanto, o contrôle não foi completamente abandonado, registrando-se algumas decisões de tribunais franceses e a lei sueca de 18 de junho de 1925, restringindo aquisição de bosques e minas, em extensão prejudicial à economia da Suécia, por magnatas industriais alemães, encobertos por companhias suecas. $\left({ }^{30}\right)$

Com a Segunda Grande Guerra, o critério do contrôle voltou à evidência, adotado pelos países beligerantes. Encontra-se na 6. ${ }^{a}$ Resolução de Bretton Wood, New Hampshire, tomada no fim da guerra a fim de evitar a fuga de capitais alemães para nações neutras. ${ }^{\left({ }^{31}\right)}$ Terminadas as hostilidades, manteve-se presente na legislação de alguns países europeus, como a Espanha, e entre os doutrinadores franceses, inconformados com o retôrno do sistema da sede social às decisões dos tribunais da França.

MAKAROV assim se expressava em 1931: “... durante a guerra mundial propôs-se o caráter inimigo das pessoas morais. Êste critério foi aplicado primeiramente pela jurisprudência inglêsa, em seguida pela legislação de outros Estados beligerantes e consagrado pelo tratado de Versailles (art. 279, b). Entretanto, não se deve considerar como um critério da nacionalidade das pessoas morais". $\left({ }^{32}\right)$ Idêntico o ponto de vista de PONTES DE MIRANDA, em 1935: "No período de liqüidação dos bens inimigos, o Tratado de Versailles, art. 296, b, o de Saint-Germain, art. 294, e o de Trianon, art. 232, abraçaram o critério do contrôle, para determinar a nacionalidade. Por que? Porque não se tratava de Direito Internacional Privado, mas de distribuição do Direito da Guerra". ${ }^{\left({ }^{3}\right)}$

Os acontecimento ocorridos no panorama mundial, vieram demonstrar o contrário, principalmente com o advento da Segunda Guerra Mundial que consolidou o sistema do contrôle no Direito Internacional Privado, onde ocupa, atualmente, lugar de destaque, firmando-se na doutrina, por ser o único capaz de estender prote-

\footnotetext{
29. BARBOSA L. SOBRINHO, 21/22.

30. WOLFF, 295, nota 56.

31. W. GOLDSCHMIDT, I/457.

32. BARBOSA L. SOBRINHO, 162.

33. NIBOYET, II, 361.
} 
ção às pessoas jurídicas genuinamente nacionais, contra a infiltração de capitais estrangeiros.

No Direito brasileiro, a lei 123 , de 1892, regulamentando o parágrafo único do art. 13, da Constituição de 1891, consagrava os princípios da sede social e do contrôle, ao estabelecer: "... sociedade ou emprêsa com sede no Brasil, gerida exclusivamente por cidadãos brasileiros" (art. 3, inc. I). Embora não se usasse a denominação de contrôle, o dispositivo legal aplicava êsse princípio, porquanto exigia que a pessoa jurídica fôsse controlada por brasileiros.

Posteriormente, entrou em vigor o decreto 2.304 , de 1896, aprovando o regulamento da navegação de cabotagem. Em seu art. $5 .^{\circ}$, $\S 2 .^{\circ}$, definia a sociedade brasileira, adotando os princípios do lugar da constituição alínea a); nacionalidade dos sócios (alínea b); lugar da constituição, sede social e contrôle (alínea c). $\left({ }^{34}\right.$ )

CARLOS DE CARVALHO, na Nova Consolidação, adotou os critérios do lugar da constituição, da sede social e nacionalidade dos sócios, o último sòmente para pessoas jurídicas constituídas no estrangeiro. CLÓVIS BEVILÁQUA também indicava os três critérios acima, como sendo os adotados pelo Direito Brasileiro. Portanto, o contrôle, aplicado com exclusividade na lei 123, de 1892, sofreu restrições no decreto 2.304 de 1896 e, por fim, desapareceu na Consolidação de CARLOS DE CARVALHO, na exposição de CLÓVIS BEVILÁQUA e do Direito Brasileiro.

Finalmente, passou a vigorar o decreto-lei 2.627, de 1940, consagrando os princípios do lugar da constituição e da sede social. Durante a Primeira Grande Guerra, o Brasil aderiu ao contrôle, o mesmo acontecendo, durante a guerra de 1939, pelo decreto-lei 4.807, de 7-10-1942, restrito ao período de beligerência.

Embora concordemos com ESPÍNOLA, OSCAR TENÓRIO, CLÓVIS e outros, quando afirmam que a legislação brasileira não adotou critério único para determinação da nacionalidade, evidencia-se que predomina o duplo sistema do lugar da constituição e da sede social, restando o critério da nacionalidade dos sócios para setôres específicos da vida econômica brasileira.

Resta saber se os sistemas do lugar da constituição e da sede social vêm ao encontro dos interêsses nacionais. A aplicação de qualquer dos dois, isoladamente, traria conseqüências imprevisíveis. Sòmente países econômicamente fortes, como os Estados Unidos, a Inglaterra, a Rússia, etc., aplicam o sistema do lugar da constitui-

34. BARBOSA L. SOBRINHO, 243. 
ção. Até mesmo a França exige a sede social em conjunto com o lugar da constituição. Não fôsse o prestígio que lhe empresta o Direito anglo-americano, deixaria de existir como critério autônomo.

A imprestabilidade do duplo sistema adotado pelo Direito brasileiro ressalta principalmente em face do conceito (melhor dizer: ausência de conceito) dado à sede social. Tudo funciona como se houvesse interêsse em conceder a nacionalidade brasileira e as pessoas jurídicas fizessem o favor em aceitá-la, quando, na realidade, existe "... I'intérêt politique indiscutable de traiter comme étrangère toute personne morale dont la filiation n'est pas Française pour ne pas lui permettre de bénéficier de droits dont la jouissance par la volonté du législateur, est réservée aux Français" $\left({ }^{35}\right)$ (onde se lê francesa e franceses, poder-se-ia ler: brasileira e brasileiros, respectivamente).

Com efeito, o exame mesmo superficial de numerosas pessoas jurídicas brasileiras demonstra à saciedade o caráter estrangeiro dessas emprêsas ou, então, que estamos diante de simples filiais de pessoas jurídicas estrangeiras.

Não entendemos como é possível considerar-se nacional um grupo de emprêsas em que, num total de 4.356 .950 ações, apenas 36 encontram-se em mãos de brasileiros. ${ }^{\left({ }^{36}\right)}$ Ou ainda outra, com 16 ações pertencentes a brasileiros, num total de 350.000 .

Muitos outros casos poderiam ser enumerados, em lista bastante extensa, porém, citaremos, sòmente mais um, ocorrido recentemente. Determinada pessoa jurídica brasileira tem 166.902.964 ações divididas entre oito acionistas, dos quais sete são pessoas jurídicas estrangeiras pertencentes ao mesmo grupo. O oitavo acionista é um cidadão estrangeiro residente em nosso país, com função na diretoria da emprêsa nacionalizada. $\left({ }^{37}\right)$

Conforme fizemos notar, a completa dissociação entre a realidade brasileira e o sistema adotado por nossa legislação é motivada, em grande parte, pelo entendimento vigorante no Brasil, segundo o qual não é levado em consideração o conceito de sede social fictícia, contentando-se com o declarado no estatuto e uma placa no edifício que os dirigentes convencionaram intitular como sede social.

Ora, segundo a Côrte de Apelação de Paris, em acórdão anteriormente citado, sede social é o lugar onde se reúnem as assembléias

35. Diário Oficial da União, de 15-1-69, p. 444.

36. in ROMERO DEL PRADO, $1 / 916$.

37. SAVATIER, 40. 
gerais, onde funcionam os órgãos de direção superior e o conselho de administração. THALLER, por sua vez, estabelece como sede social - local "em que residem os órgãos jurídicos da sociedade, administradores, assembléias gerais e onde se tratam os contratos e assuntos que se referem à marcha da emprêsa". $\left({ }^{38}\right)$

Dentro da orientação acima, notamos que grande número de pessoas jurídicas, pretensamente nacionais, não possuem sede social em nosso país. Na verdade, os órgãos de direção superior, os conseIhos de administração dessas emprêsas funcionam no estrangeiro, de onde partem os programas a serem obedecidos pelos diretores residentes em nosso país, diretores êsses, na realidade, funcionários categorizados da matriz estrangeira a quem prestam contas. Em muitos casos, não há assembléias e sim o encontro de dois ou três procuradores de acionistas em obediência às exigências legais.

Portanto, muitas pessoas jurídicas brasileiras não passam de simples filiais de emprêsas estrangeiras, às quais deveríamos aplicar o ensinamento de SAVATIER para determinar a nacionalidade dessas filiais: "Cette théorie du contrôle s'impose particulièrement en matière de sociétés filiales. On désigne ainsi les sociétés qui fondent, dans un autre pays, une société appartenant elle-même à un pays déterminé. Ces sociétés ont leur siège social et leur centre d'explotation dans le pays où elles sont fondées. Quant à leur constitution et à leur vie juridique, elles obéissent à la loi de ce pays. Mais la société-mère n'en conserve pas moins la majorité des actions. Et, par suite, c'est elle qui en choisit les organes. Au point de vue de la jouissance des droits civils dans le pays où elle fonctionne, la société filiale a donc la même nationalité de la société-mère". $\left({ }^{39}\right)$

Como reação à orientação de nossa lei e a interpretação pacificamente aceita, registramos duas tentativas, procurando definir, como brasileiras a pessoa jurídica genuinamente brasileira.

O primeiro projeto é de autoria de GABRIEL DE REZENDE PASSOS, adotando os sistemas do lugar da constituição, da sede social e do contrôle, ao estabelecer que serão brasileiras as sociedades: a) constituídas no Brasil; b) com mais de $50 \%$ de seu capital, em ações nominativas ou quotas pertencentes a pessoas residentes, permanente e efetivamente no Brasil; c) dirigidas efetivamente por brasileiros; d) com sede principal no Brasil. Estipulava a ausência de laços de subodinação ou de dependência com firmas, grupos, trusts ou pessoas físicas estrangeiras.

38. VALADÃO, 456.

39. BARBOSA L. SOBRINHO, 243. 
BARBOSA LIMA SOBRINHO foi quem elaborou o outro projeto de le:. Estabelecia dois tipos de pessoas jurídicas nacionais: pela forma e pela composição de seu capital. Na primeira modalidade mantém os sistemas do lugar da constituição e da sede social.

No segundo tipo, definia como brasileiras as sociedades constituídas em nossa Pátria, com sede social no Brasil e maioria de capital pertencente a brasileiros ou estrangeiros, com mais de 10 anos de residência. Em alguns casos, dispensava a direção exercida por brasileiros, admitindo que dois têrços do capital pertencessem a estrangeiros, com mais de 10 anos de residência. Apesar disso, vários dispositivos existem, no projeto, evitando o contrôle por parte de estrangeiros não residentes, holdings e trusts estrangeiros.

O Prof. HAROLDO VALADÃO considera confusa e incompleta a conceituação de nacionalidade brasileira, pela forma e pela composição do capital. Entendemos não se justificar, doutrinàriamente, as duas modalidades de nacionalidade. A diferença básica entre as duas seria o contrôle, adotado no segundo e excluído no primeiro. Parecenos que LIMA SOBRINHO pretendeu evitar atritos com os defensores das pessoas jurídicas que já haviam adquirido nacionalidade brasileira, amenizando, assim, o árduo caminho a ser palmilhado pelo projeto.

É bom ressaltar que não se cogita de vedar o funcionamento de emprêsas estrangeiras em nosso território e sim de distinguir as verdadeiramente nacionais das estrangeiras a fim de que sòmente aquelas possam usufruir de benefícios instituídos pelo legislador para as pessoas jurídicas brasileiras ou, então, para que o contribuinte suporte o ônus impôsto pela necessidade de expansão de atividade vital, apenas de pessoas jurídicas nacionais e não de grupos estrangeiros, conforme observou EUGÊNIO GUDIN: "o verdadeiro sentido da nacionalização da Light é de nos passar a incumbência de encontrar êsses capitais. . ." $\left({ }^{40}\right)$

Para os que dizem tratar-se de "demonstração de nacionalismo à outrance" é bom lembrar que, no mundo atual, mesmo as grandes potências adotam medidas de franco protecionismo às suas emprêsas quer no âmbito interno quer no internacional. Os Estados Unidos estabelecem sanções econômicas (suspensão de ajuda) às nações que desapropriarem, sem indenização adequada, emprêsas com cincoenta por cento, pelo menos, do capital pertencentes a pessoas físicas ou jurídicas norte-americanas, independentemente da naciona-

40. W. BATALHA, $11 / 269$. 
lidade aparente. MARTIN WOLFF acentua que o Direito está obrigado a descobrir os que controlam a pessoa jurídica, quando, mesmo em tempo de paz, "um estado deseja proibir que sua indústria nacional, comércio ou agricultura passe para mãos de estrangeiros". $\left({ }^{41}\right)$

O duplo critério predominante no Direito brasileiro enseja que pessoas jurídicas, sediadas em nosso país e constituídas de acôrdo com nossa lei, porém controladas por estrangeiros residentes no exterior, adquiram nacionalidade brasileira. Por outro lado, o completo desconhecimento do conceito de sede social proporciona a grande número de filiais de emprêsas estrangeiras tornarem-se, aparentemente, pessoas jurídicas brasileiras.

Portanto, diante da evidente deficiência do duplo sistema do lugar da constituição e da sede social, impõe-se a adoção urgente do contrôle para, em conjunto com os dois critérios vigorantes, atribuir nacionalidade brasileira a pessoas jurídicas que realmente tenham essa nacionalidade e não, apenas, em aparência.

Longe de constituir-se em novidade, conforme vimos, o contrôle tem tradição em nosso Direito, podendo-se afirmar que foi o primeiro sistema a estabelecer divisor entre as pessoas jurídicas estrangeiras e as nacionais. Graças a êle, segundo o Deputado Almirante ANTONIO NOGUEIRA, o Brasil possuía marinha mercante durante a primeira grande guerra, quando os países europeus não dispunham de navios para atender as suas necessidades e, muito menos, às nossas. $\left({ }^{42}\right)$

A adoção do contrôle seria, principalmente, no sentido de sòmente conceder nacionalidade brasileira, originária ou por mudança (art. 71, do dec.-lei 2.627/40), às pessoas jurídicas que não tivessem qualquer subordinação, direta ou indireta, a holdings, trusts e pessoas jurídicas estrangeiras ou pessoas físicas residentes fora do Brasil.

Dessa forma, como acontecia nos projetos GABRIEL PASSOS e BARBOSA LIMA SOBRINHO, teria nossa nacionalidade a pessoa jurídica controlada por brasileiros ou estrangeiros radicados, durante certo número de anos, em nosso país. O estrangeiro radicado no Brasil seria equiparado ao brasileiro, providência essa adequada a país de imigração. O perigo apontado por PONTES DE MIRANDA, ao referir-se à sede social, seria perfeitamente contornado por meio de legislação própria ao tempo de guerra.

41. WOLF, 295.

42. BARBOSA L. SOBRINHO, 161. 
Como conseqüência do sistema do contrôle, a subordinação a grupos estrangeiros impediria a nacionalização e, se essa subordinação fôsse posterior, importaria na perda da nacionalidade, além de outras sanções.

\section{BIBLIOGRAFIA}

1 - LeREBOURS - PIGEONNIÈRE, Précis de Droit Int. Privé, 1948, Dalloz.

2 - RENÉ SAVATIER - Cours de Dr. Int. Privé, Paris, 1953.

3 - PONTES DE MIRANDA - Trat. de Dir. Int. Priv., Rio, 1935.

4 - eduardo espínOla e E. ESPínOlA FILHO - Trat. de Dir. Civil Bras. vol. V, Rio, 1940.

5 - ClÓVIS BEVILAQUA - Dir. Int. Priv., Rio, 1938.

6 - WERNER GOLDSCHMIDT - Sisłema y Filosofia Del Derecho Int. Privado, Buenos Aires, 1954.

7 - HAROLDO VALADÃO - Dir. Int. Priv., Rio, 1968.

8 - BARBOSA LIMA SOBRINHO - Nacionalidade de Pes. Jurídica, Minas, 1963.

7 - HENRI BATIFFOL - Dr. Int. Privé, Paris, 1967.

10 - A. N. MAKAROV - Précis de Dr. Int. Privé, Paris, 1933, tradução de NOLDE et PEREVERZEFF.

11 - WILSON BATALHA - Tratado Elementar de Dir. Int. Priv., São Paulo, 1961.

12 - NIBOYET - Traité de Dr. Int. Privé, Sirey, 1951.

13 - ROMERO DEL PRADO - Manual de Derecho Int. Privado, B. Aires, 1944.

14 - OSCAR TENÓRiO, Dir. Int. Priv., Rio, 1955.

15 - ANDRÉ WEISS - Manual de Dr. Int. Privé, Paris, 1914.

16 - MARTIN WOLFF - Derecho Internacional Privado, Espanha, 1958, tradução de ANTONIO MARIN LÓPEZ.

17 - Jurisprudence de Dr. Int. Privé, Sirey, 1961.

18 - JEAN CHAPRAT - Dr. Int. Privé (La Composition Écrite), Paris, 3.a ed.

19 - ESTANISLAO ZEBALLOS - Rev. do Supremo Tribunal, vol. IX, Out./1916, Conferência pronunciada na Fac. de Buenos Aires, em 23 e 26 de julho de 1916.

20 - GIUSEPPE CASSONI - La Nazionalizzazione delle Società e il Diritło Internazionale Privało, 1959, Milão. 